\section{BACKGROUND TO THE PUBLICATION}

The publication of these excavations at the Roman fort of Doune has a convoluted history. The publication of the initial 1999 excavation (Moloney 1999a, 1999b) was in the process of being refereed by Britannia when the second phase of work was commissioned in 2008 (Masser 2008). It was therefore considered best practice to delay publication until the two phases of work could be combined into a single paper. During the final preparation of this combined 1999/2008 paper, a third phase of work was commissioned in 2010 and again publication was delayed, with the hope of incorporating all three phases into a single publication report. Unfortunately, due to no explicit reference being made by Stirling Council (as both the client and the curator) of a requirement to fund the publication of the 2008 and 2010 excavations, Headland Archaeology (UK) Ltd was only contracted to produce assessment reports for these phases of work (Masser 2008, 2010). In a bid to present here (at minimum) a summary of the results for the entire archaeological fieldwork undertaken within the fort between 1999 and 2010, this paper is a detailed report of the 1999 and 2008 excavations (an edited version of the combined $1999 / 2008$ paper) with a summary of the results of the 2010 excavation. 